\title{
Prolonged viral shedding of SARS-CoV-2 and related factors in symptomatic COVID-19 patients: a prospective study
}

Hui Long ${ }^{1 \dagger}$, Jing Zhao ${ }^{2 \dagger}$, Hao-Long Zeng ${ }^{3}$, Qing-Bin Lu ${ }^{4}$, Li-Qun Fang ${ }^{2}$, Qiang Wang ${ }^{5 *}$, Qing-Ming Wu ${ }^{5^{*}}$ and Wei Liu $\mathrm{Lu}^{2 *}$

\begin{abstract}
Background: The temporal relationship between SARS-CoV-2 and antibody production and clinical progression remained obscure. The aim of this study was to describe the viral kinetics of symptomatic patients with SARS-CoV-2 infection and identify factors that might contribute to prolonged viral shedding.

Methods: Symptomatic COVID-19 patients were enrolled in two hospitals in Wuhan, China, from whom the respiratory samples were collected and measured for viral loads consecutively by reverse transcriptase quantitative PCR (RTqP(R) assay. The viral shedding pattern was delineated in relate to the epidemiologic and clinical information.

Results: Totally 2726 respiratory samples collected from 703 patients were quantified. The SARS-CoV-2 viral loads were at the highest level during the initial stage after symptom onset, which subsequently declined with time. The median time to SARS-CoV-2 negativity of nasopharyngeal test was 28 days, significantly longer in patients with older age (> 60 years old), female gender and those having longer interval from symptom onset to hospital admission (> 10 days). The multivariate Cox regression model revealed significant effect from older age ( $\mathrm{HR} 0.73,95 \% \mathrm{Cl} 0.55-$ 0.96), female gender ( $\mathrm{HR} 0.72,95 \% \mathrm{Cl} 0.55-0.96$ ) and longer interval from symptom onset to admission ( $\mathrm{HR} 0.44,95 \%$ CI 0.33-0.59) on longer time to SARS-CoV-2 negativity. The lgM antibody titer was significantly higher in the low viral loads group at 41-60 days after symptom onset. At the population level, the average viral loads were higher in early than in late outbreak periods.
\end{abstract}

Conclusions: The prolonged viral shedding of SARS-CoV-2 was observed in COVID-19 patients, particularly in older, female and those with longer interval from symptom onset to admission.

Keywords: COVID-19, SARS-CoV-2, Viral shedding, Antibody, Risk factor

*Correspondence: wangqiang@wust.edu.cn; wuhe9224@sina.com; Iwbime@163.com; liuwei@bmi.ac.cn

${ }^{\dagger}$ Hui Long, Jing Zhao have contributed equally to this work

2 State Key Laboratory of Pathogen and Biosecurity, Beijing Institute of Microbiology and Epidemiology, Beijing, People's Republic of China

${ }^{5}$ Institute of Infection, Immunology and Tumor Microenvironment, Hubei Province Key Laboratory of Occupational Hazard Identification and Control, Medical College, Wuhan University of Science and Technology, Wuhan, People's Republic of China

Full list of author information is available at the end of the article

\section{Background}

COVID-19 pandemic caused by severe acute respiratory syndrome coronavirus 2 (SARS-CoV-2) has affected over 166.9 million patients with more than 3.5 million deaths all over the world until May 24, 2021 [1]. Despite of stringent control measures, COVID-19 continues to circulate worldwide, severely disrupted the health care system and halted socioeconomic activities. The confirmation of SARS-CoV-2 infection in clinical practice relies on the detection of virus RNA in various types of samples 
during the acute phase of infection. The prolonged shedding of virus RNA in various body fluids beyond the acute phase of infection has been reported in various studies [2-5], which is auxiliary in making the clinical diagnosis and preventing of onward virus transmission. COVID-19 encompasses a heterogeneous spectrum of illness, ranging from asymptomatic and mild infections, to severely ill cases in 4-16\% [6,7]. How were the duration and magnitude of SARS-CoV-2 RNA can be related to clinical phenotypes had been investigated in the early phase of the epidemic and commonly in small-scale studies, which results lacked replication by large scale study $[8,9]$. As the disease progressed, whether this association remained unchanged remained to be explored. Viral replication and overwhelming immune responses are believed to contribute to the clinical outcome of COVID19, however, the temporal relationship between viral load and antibody production and clinical progression remained obscure. Here we performed a hospital-based study on two cohorts of confirmed symptomatic COVID19 patients to acquire a detailed understanding of the dynamics of SARS-CoV-2 infection, to record the time that detection of SARS-CoV-2 turned to negative for all the patients and to estimate the factors.

\section{Methods}

\section{Patient enrollment}

From January 2020 to March 2020, COVID-19 patients were recruited from two COVID-19 referral hospitals in Wuhan, Hubei Province, i.e., Tongji hospital and Tianyou hospital. The COVID-19 was diagnosed based on the standard protocol released by the National Health Commission of China. Four types of detection kits ( $\mathrm{Da} \mathrm{An}$ Gene, BioGerm, TIANLONG Technology and HUIRUI Co., Ltd) were used to test for SARS-CoV-2 RNA in the collected nasopharyngeal swab (NPS) specimens following the World Health Organization (WHO) guidelines (World Health Organization, 2020) [10-12]. For the confirmed COVID-19 patients, sequential NPS samples were collected for SARS-CoV-2 RNA quantification by the cycle threshold value (Ct value) during their hospitalization until discharge or death. The lower detection limit of assay was $1 \times 10^{3}$ copies $/ \mathrm{mL}$. Totally 45 cycles have been run for RT-qPCR test, and samples with $\mathrm{Ct}$ value $<40$ were considered as positive, while $\mathrm{Ct}$ value $\geq 40$ and undetectable $\mathrm{Ct}$ value were considered as negative. Two target genes, the nucleocapsid protein $(\mathrm{N})$ and open reading frame 1ab (ORF1ab) genes were simultaneously amplified, and the samples positive for either target were considered as positive. Across the study, the same protocols and reagents were used for the tests. Time to SARSCoV-2 RNA negativity was defined as the days of interval between the date of disease onset and the date of SARSCoV-2 RNA turning negative.

The serum samples collected at the diagnosis and before discharge were used for the measurement of SARS-CoV-2-specific IgM and IgG antibodies by using a seroFlash SARS-CoV-2 IgG/IgM ELISA fast kit (Epigentek, USA) with a recombinant SARS-CoV-2 antigen (Spike protein).

\section{Data collection}

Medical chart review was conducted for the recruited patients to collect information regarding demographics, medical history, disease onset (the 1st day of reporting symptoms consistent with COVID-19) and clinical phenotypes. The severity of illness was defined into severe or mild disease according to the 7th edition of Chinese Clinical Guidance for COVID-19 Pneumonia Diagnosis and Treatment issued by the National Health Commission of the People's Republic of China by a group of trained medical staff [12].

\section{Statistical analyses}

Continuous variables were expressed as median and interquartile range (IQR) or mean \pm standard deviation (SD) and categorical variables were expressed as frequencies. Fisher exact test, Wilcoxon rank sum test, or log rank test was used for inter-group comparisons and logistic regression model for multivariable analysis. Chisquare test or Wilcoxon rank sum test was performed depending on parametric or nonparametric data. Survival analysis was performed using Kaplan-Meier curves and Cox regression model to identify potential factors that were related to the time to SARS-CoV-2 RNA negativity. All statistical analyses were performed using the $\mathrm{R}$ software (version 3.5.3). A two-sided $P$ value $<0.05$ was considered statistically significant.

\section{Results}

\section{Patient recruit and baseline information}

A total of 2726 NPS samples from 703 enrolled patients were quantified for SARS-CoV-2 RNA (median of 3 samples per patient). The median age of the study patients was 63 years (range 10-92 years), and 332 (47.2\%) were male. The median interval from symptom onset to the hospital admission was 11 days (IQR 7-15). At least one underlying medical condition was recorded from 290 (41.3\%) patients, comprised of hypertension in 236 (33.6\%), diabetes in 99 (14.1\%), cardiovascular disease in $53(7.5 \%)$ and cerebral infarction in $19(2.7 \%)$ of the patients. Most of the patients $(87.6 \%, 616 / 703)$ had mild disease and the remaining $12.4 \%$ had severe disease. The commonly seen clinical symptoms, including fever, cough, fatigue, anhelation, nausea, diarrhea and anorexia, 
were observed with comparable frequencies between mild and severe patients (all $\mathrm{P}>0.05$, Table 1 ).

\section{Dynamic profile of viral load and detection rates of SARS-CoV-2}

The viral load and positive rates using both $\mathrm{N}$ and ORF specific primers showed declining trends (Fig. 1). The specimens collected in the initial stage of disease onset at the diagnosis had the highest positive rate (mean of $42.9 \%$ for $\mathrm{N}$ gene on the 3rd day of symptom onset and $50 \%$ for ORF gene on the 1st day of symptom onset), followed by consistently decrease thereafter, till to $5.9 \%$ for $\mathrm{N}$ gene and $0 \%$ for ORF at the last observation. In a consistent manner, the $\mathrm{Ct}$ value of $\mathrm{N}$ and ORF genes increased obviously from $34.76 \pm 7.18$ and $33.06 \pm 8.18$ (mean $\pm S D)$ at the diagnosis to $39.54 \pm 1.71$ and $39.64 \pm 1.53$ at 21 st day after symptoms onset, respectively, followed by a plain level of $\mathrm{Ct}$ value of 40 that last for the remaining tests. According to the fitted temporal curves, both viral load and positive rates correlated negatively with time after onset of symptoms ( $\mathrm{R}^{2}$ of $\mathrm{Ct}$ values were 0.96 and 0.92 for $\mathrm{N}$ and ORF genes; $\mathrm{R}^{2}$ of positive rates were 0.93 and 0.94 for $\mathrm{N}$ and $\mathrm{ORF}$ genes, all $\mathrm{P}<0.001$ ), and with a faster decay of positive rate for ORF than $\mathrm{N}$ gene (decay rate, $0.83 \%$ vs. $0.63 \%$ ) (Fig. 1 ).

\section{The prolonged viral shedding and associated factors} Among 240 COVID-19 patients who had over three SARS-CoV-2 RNA tests, 214 patients had converted negative to the end of the observation. An overall CFR of $4.2 \%(9 / 214)$ was obtained. Inter-group comparisons showed median time to SARS-CoV-2 RNA negativity was significant longer in patients who were female, aged $>60$ years and with longer interval ( $>10$ days) from symptoms onset to hospital admission $(\mathrm{P}=0.034$, $\mathrm{P}=0.003$ and $\mathrm{P}<0.001$, respectively, Fig. 2A). Based on $\mathrm{N}$ gene, 205 (85.4\%) COVID-19 patients had converted negative to the end of the observation (Additional file 1: Table 1). The median time of SARS-CoV-2 RNA negativity was 28 days (IQR 22-36), 100 patients had viral shedding $>28$ days (long viral shedding, LVS group), and 105 patients has viral shedding $\leq 28$ days (short viral shedding, SVS group) in the NPS samples. Inter-group comparisons disclosed that the LVS group had significantly higher frequency of female (55\% vs. $39 \%$ ), older age (>60 years, $66 \%$ vs. $49.5 \%$ ), with longer interval from

Table 1 Demographics and clinical characteristics of recruited COVID-19 patients

\begin{tabular}{|c|c|c|c|c|}
\hline Characteristics & $\begin{array}{l}\text { Total } \\
(n=703)\end{array}$ & $\begin{array}{l}\text { Mild } \\
(n=616)\end{array}$ & $\begin{array}{l}\text { Severe } \\
(n=87)\end{array}$ & P value \\
\hline Age, years, median (IQR) & $63(50-70)$ & $62(49-69)$ & $67(57-76)$ & $<0.001$ \\
\hline$\leq 60$ & $307(43.7)$ & $281(45.6)$ & $26(29.9)$ & $0.006^{*}$ \\
\hline$>60$ & $396(56.3)$ & $335(54.4)$ & $61(70.1)$ & \\
\hline Sex, male, n (\%) & $332(47.2)$ & $281(45.6)$ & $51(58.6)$ & $0.023^{*}$ \\
\hline Interval\#, days, median (IQR) & $11(7-15)$ & $11(7-15)$ & $10(7-15)$ & 0.808 \\
\hline$\leq 10$ & $348(49.5)$ & $303(49.2)$ & $45(51.7)$ & 0.658 \\
\hline$>10$ & $355(50.5)$ & $313(50.8)$ & $42(48.3)$ & \\
\hline Length of stay, days, median (IQR) & $21(14-24)$ & $22(15-24)$ & $18(10-23)$ & 0.001 \\
\hline \multicolumn{5}{|c|}{ Clinical manifestation on admission, $\mathrm{n}(\%)$} \\
\hline Fever & $533(75.8)$ & $467(75.8)$ & $66(75.9)$ & 0.992 \\
\hline Cough & $438(62.3)$ & $387(62.8)$ & $51(58.6)$ & 0.449 \\
\hline Fatigue & $174(24.8)$ & $149(24.2)$ & $25(28.7)$ & 0.358 \\
\hline Anhelation & $178(25.3)$ & $149(24.2)$ & $29(33.3)$ & 0.066 \\
\hline Nausea & $57(8.1)$ & $50(8.1)$ & $7(8.0)$ & 0.982 \\
\hline Diarrhea & $115(16.4)$ & $104(16.9)$ & $11(12.6)$ & 0.317 \\
\hline Anorexia & $72(10.2)$ & 65 (10.6) & $7(8.0)$ & 0.471 \\
\hline Comorbidity, n (\%) & $290(41.3)$ & $245(39.8)$ & $45(51.7)$ & 0.034 \\
\hline Hypertension & $236(33.6)$ & $199(32.3)$ & $37(42.5)$ & 0.059 \\
\hline Diabetes & $99(14.1)$ & $83(13.5)$ & $16(18.4)$ & 0.217 \\
\hline Cardiovascular disease & $53(7.5)$ & $47(7.6)$ & $6(6.9)$ & 0.808 \\
\hline Cerebral infarction & $19(2.7)$ & $15(2.4)$ & $4(4.6)$ & 0.417 \\
\hline
\end{tabular}

IQR interquartile range

*Significant difference between mild and severe patients after adjusting for age, sex and presence of comorbidity

\# Indicates interval between disease onset and hospital admission 


\section{A}
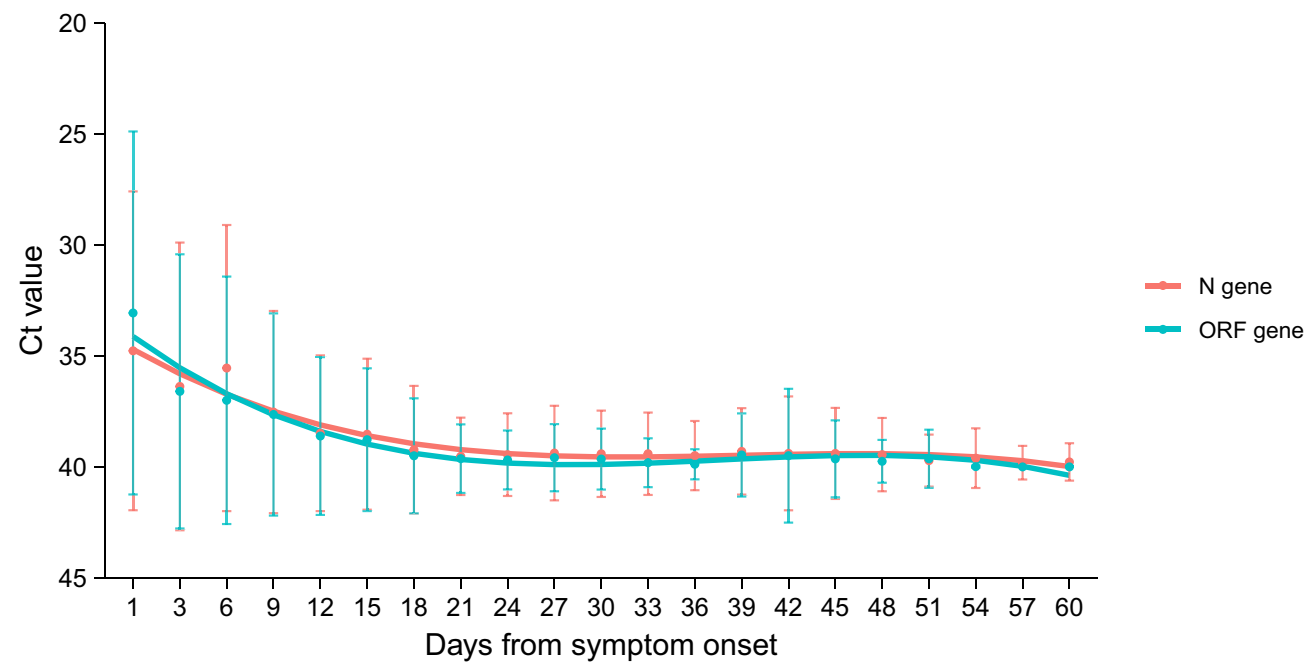

B

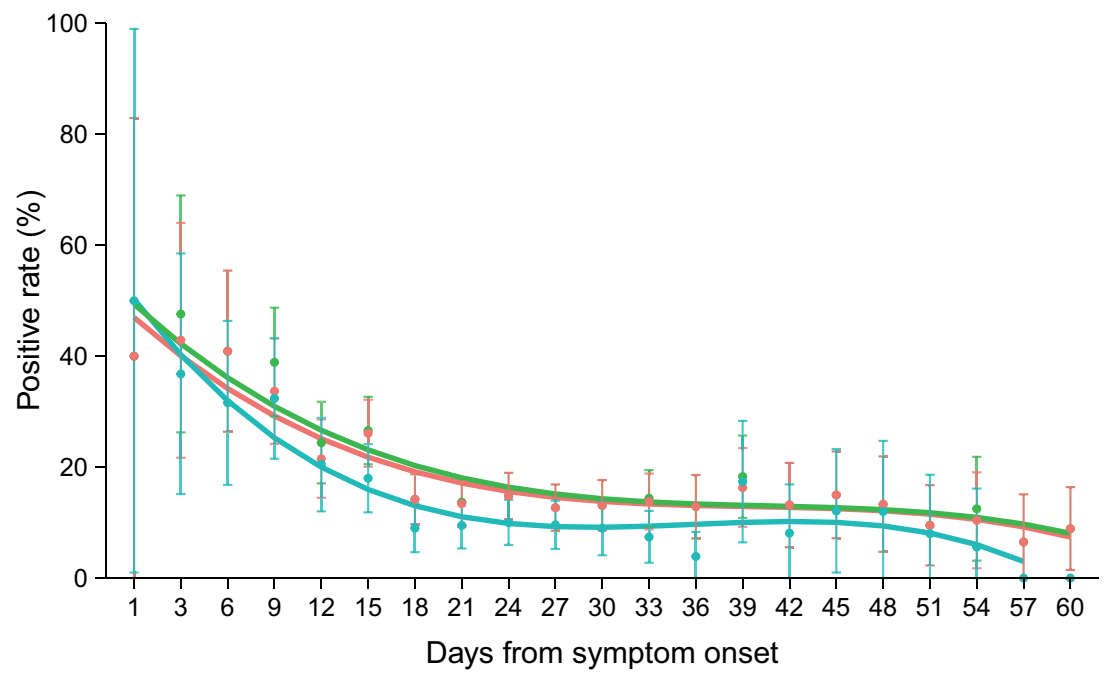

Fig. 1 Dynamic profile of viral loads and positive rates of SARS-COV-2 based on N and ORF genes amplification among COVID-19 patients during the whole process of hospitalization. A The dynamic profile of viral loads [cycle threshold (Ct) value] measured by RT-qPCR assay using N and ORF specific primers in COVID-19 patients; $\mathbf{B}$ the dynamic profile of positive rates measured by $N$ and ORF specific primers in COVID-19 patients. The positive for SARS-CoV-2 was defined by either positive for $\mathrm{N}$ or ORF of SARS-CoV-2. When applicable, mean \pm standard deviation (SD) of Ct value is shown. Dots and error bars denote means and SDs, respectively

symptom onset to hospital admission (12 vs. 8 days), longer length of hospitalization (24 vs. 23 days) and higher frequency of cough (73\% vs. $55.2 \%$ ) than the SVS group (all $\mathrm{P}<0.05$ ). Based on the test of ORF gene, the median duration of viral shedding was 24 days (IQR 22-29), the long viral shedding $>24$ days was significantly associated with longer interval from symptom onset to admission (11 vs. 8 days) than those with short viral shedding $(\mathrm{P}<0.05$, Additional file 1: Table 1$)$. Higher frequency of severe disease was observed in the LVS group than in SVS group, which difference, however, was insignificant $(21.4 \%$ vs. $7.1 \%, \mathrm{P}=0.596)$.

\section{Survival analysis based on time to SARS-CoV-2 RNA negativity}

The univariate Cox regression model disclosed that patients with delayed negative conversion ( $>28$ days according to $\mathrm{N}$ gene test) was related to female, older age ( $>60$ years) and longer interval from symptom onset to admission ( $>10$ days) (all $\mathrm{P}<0.05$, Fig. 2A). Likewise, 


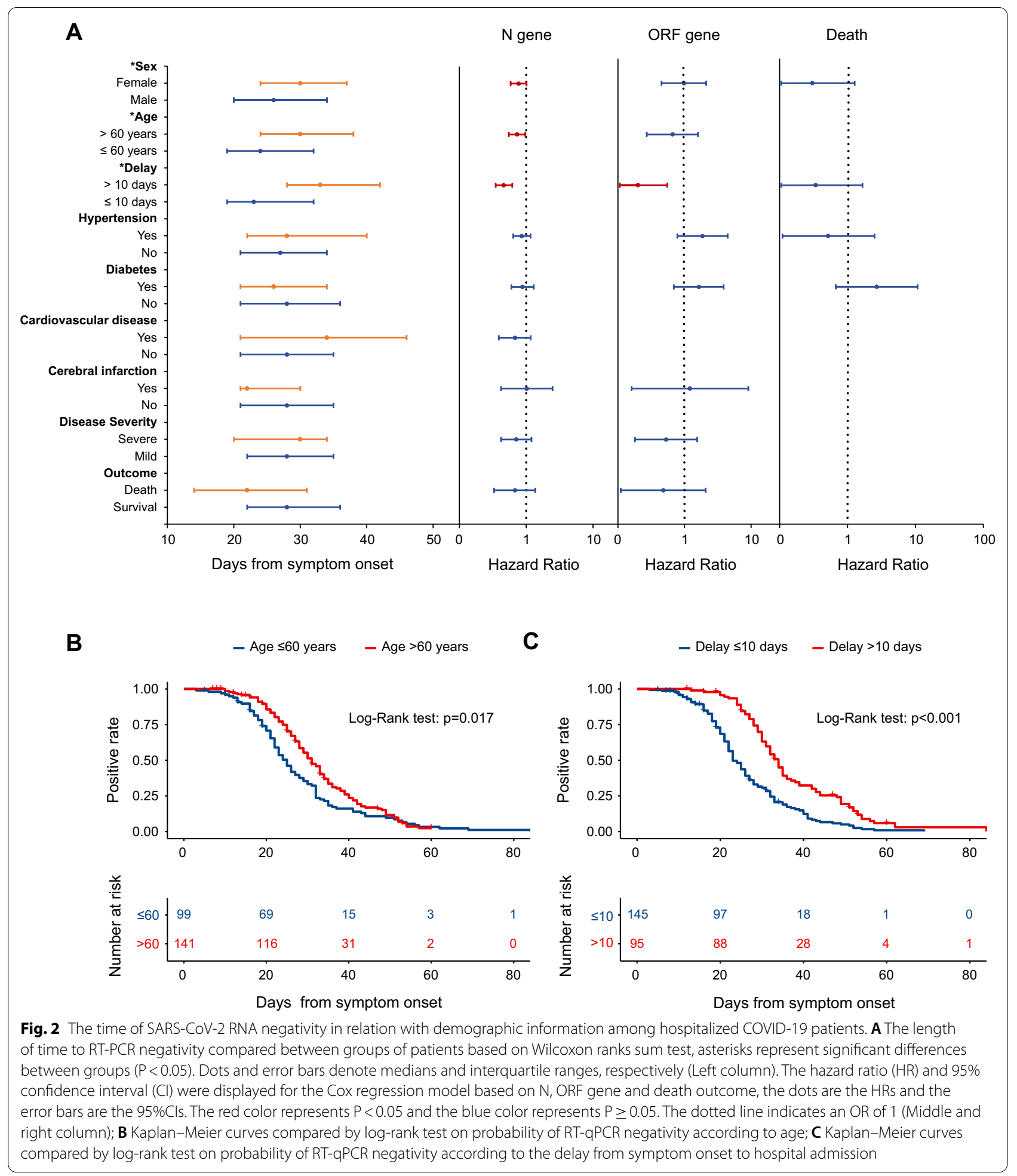

Kaplan-Meier curves revealed the same effect from older age ( $>60$ years), and interval $>10$ days from symptom onset to admission on longer time to SARS-CoV-2 RNA negativity $(\mathrm{P}=0.017$ and $\mathrm{P}<0.001$, respectively,
Fig. $2 \mathrm{~B}$ and $\mathrm{C}$ ). In a consistent manner, the multivariate Cox regression model analysis revealed that interval from symptom onset to admission $>10$ days, female gender and older age $>60$ years were related to late negative 
conversion (HR 0.44, 95\% CI 0.33-0.59, HR 0.72, 95\% CI 0.55-0.96 and HR 0.73, 95\% CI 0.55-0.96, respectively, all $\mathrm{P}<0.05$, Table 2). No significant effect on time to SARS-CoV-2 negativity was observed from disease severity based on either univariate or multivariate Cox regression model $(\mathrm{P}>0.05$, Table 2$)$. When the recorded clinical manifestations on admission were further evaluated, no association was observed between any symptom (fever, cough, fatigue, anhelation, nausea, diarrhea or anorexia) and prolonged viral shedding (Additional file 1: Table 2).

\section{Anti-SARS-CoV-2 IgM and IgG antibody in relation to viral load}

Considering that IgM and IgG antibodies were only detectable around 20th day after symptom onset, we divided the clinical progression into two stages (21st40th day and 41st-60th day post disease onset), and within each stage, the correlation between antibody levels and SARS-CoV-2 viral load were separately investigated. Based on the minimum $\mathrm{Ct}$ value per patient, high viral loads that exceeded mean $\mathrm{Ct}$ (herein $\mathrm{Ct}$ of 36.3 for $\mathrm{N}$ gene and $\mathrm{Ct}$ of 37.9 for ORF gene) and low viral loads that below mean $\mathrm{Ct}$ were grouped into the HVL and LVL group, separately.

The geometric mean reciprocal titer (GMRT) of the antibodies evaluated during two stages were separately compared between HVL vs. LVL groups, and only significantly higher IgM antibody titer was found in the LVL group based on the $\mathrm{N}$ gene evaluation at the second

Table 2 The association between longer time to SARS-CoV-2 RNA negativity and age, sex, interval between disease onset and hospital admission, disease severity for COVID-19 patients

\begin{tabular}{|c|c|c|c|c|}
\hline \multirow[t]{2}{*}{ Characteristics } & \multicolumn{2}{|l|}{ Crude } & \multicolumn{2}{|l|}{ Adjusted* } \\
\hline & HR $(95 \%$ Cl) & P value & $\mathrm{HR}(95 \% \mathrm{Cl})$ & P value \\
\hline \multicolumn{5}{|l|}{ Age, years } \\
\hline$\leq 60$ & Reference & & Reference & \\
\hline$>60$ & $0.72(0.55-0.95)$ & 0.019 & $0.73(0.55-0.96)$ & 0.025 \\
\hline \multicolumn{5}{|l|}{ Sex } \\
\hline Male & Reference & & Reference & \\
\hline Female & $0.79(0.60-1.03)$ & 0.083 & $0.72(0.55-0.96)$ & 0.023 \\
\hline \multicolumn{5}{|l|}{ Interval", days } \\
\hline$\leq 10$ & Reference & & Reference & \\
\hline$>10$ & $0.45(0.34-0.60)$ & $<0.001$ & $0.44(0.33-0.59)$ & $<0.001$ \\
\hline \multicolumn{5}{|l|}{ Disease severity } \\
\hline Mild & Reference & & Reference & \\
\hline Severe & $0.72(0.44-1.21)$ & 0.217 & $0.72(0.42-1.21)$ & 0.216 \\
\hline
\end{tabular}

$H R$ hazard ratio; $\mathrm{Cl}$ confidence interval

*Independent variables including age, sex and any comorbidity were included into multivariate Cox regression model

\# Indicates interval between disease onset and hospital admission. The univariate and multivariate Cox regression model were used in the analysis stage (Additional file 1: Fig. 1A and B). No significant difference in IgG antibody titer was observed between LVL and HVL groups during either stages (Additional file 1: Fig. $1 C$ and D).

\section{Outbreak kinetics of viral loads level}

We sought to determine if the SARS-CoV-2 viral loads of patients upon admission to the hospital changed over the course of the outbreak, regardless of outcome. Based on the symptom onset date of the patients, three outbreak stages (early, middle and late) were classified to attain comparable case numbers among three stages, i.e., with disease onset from 1st to 24th January 2020 (red line, 229 patients), 25th to 30th January 2020 (green line 245 patients), and 31st January to 5th March 2020 (blue line, 228 patients). The viral load initially evaluated before therapy from each patient were plotted over the course of three periods and fitted to a polynomial regression. GEE models based on either $\mathrm{N}$ or ORF gene, demonstrated significantly lower viral loads from the patients hospitalized at the third stage when compared with those hospitalized at early epidemic after adjusting for the potential effect from age, sex, days from symptom onset to admission, and disease severity (OR 1.53, 95\% CI 1.07-2.20 for $\mathrm{N}$ gene; OR 1.94, 95\% CI 1.32-2.87 for ORF gene; both $\mathrm{P}<0.05$, Additional file 1: Table 3 and Fig. 3).

\section{Discussion}

In the current cohort study, the temporal pattern of viral shedding from NPS were determined, and compared in relate to their demographic features and the clinical severity. We found the peak viral load occurred early for both genes, similar to He's studies [13], which decreased gradually after onset of symptoms, as patient's immune system responded to infection. Moreover, moderate level of viral shedding was still present at 21st day after onset of symptoms, which decreased to positive rate of $0.7 \%$ among the patients tested for SARS-CoV- 2 at the end of observation of more than 2 months post disease. We found that the median time to SARS-CoV-2 negativity in NPS was 26 days with 95th percentile of 53 days, thus detection of virus RNA in NPS samples at the 60th day after illness onset should be a low-probability event, beyond the 95th percentile limit.

Long viral shedding has been previously recorded, from 4 weeks in Zheng's study and 20 days in To et al's study $[8,14]$. Zheng et al. also demonstrated longer time until loss of virus RNA detection in severe cases than in mild cases [8]. Zhou et al. found prolonged presence of SARS-CoV-2 viral RNA in 137 samples as long as 37 days [15]. In contrast, Lan et al. and Lescure et al. reported positive rRT-PCR detection not exceeding 2 weeks, but only based on small sample size [5, 


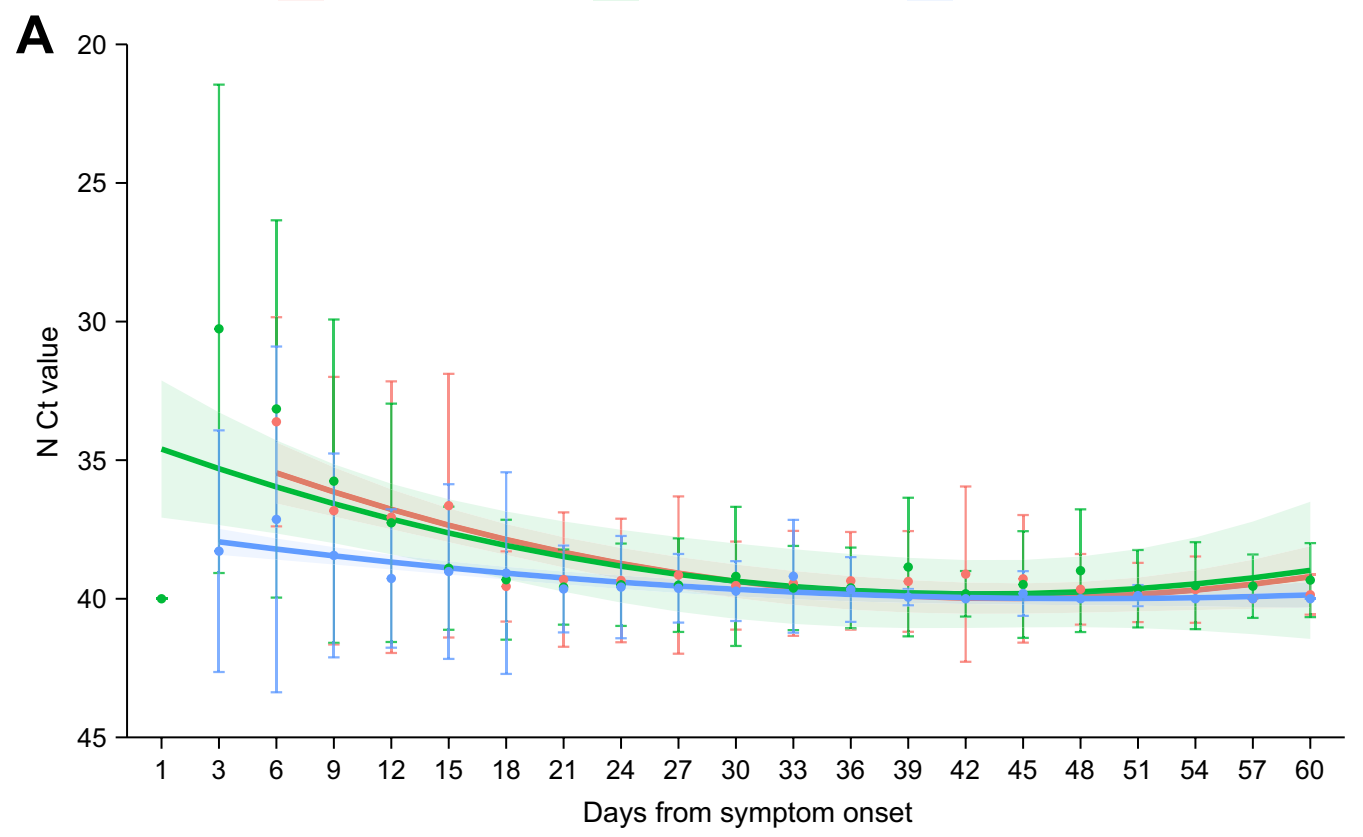

B

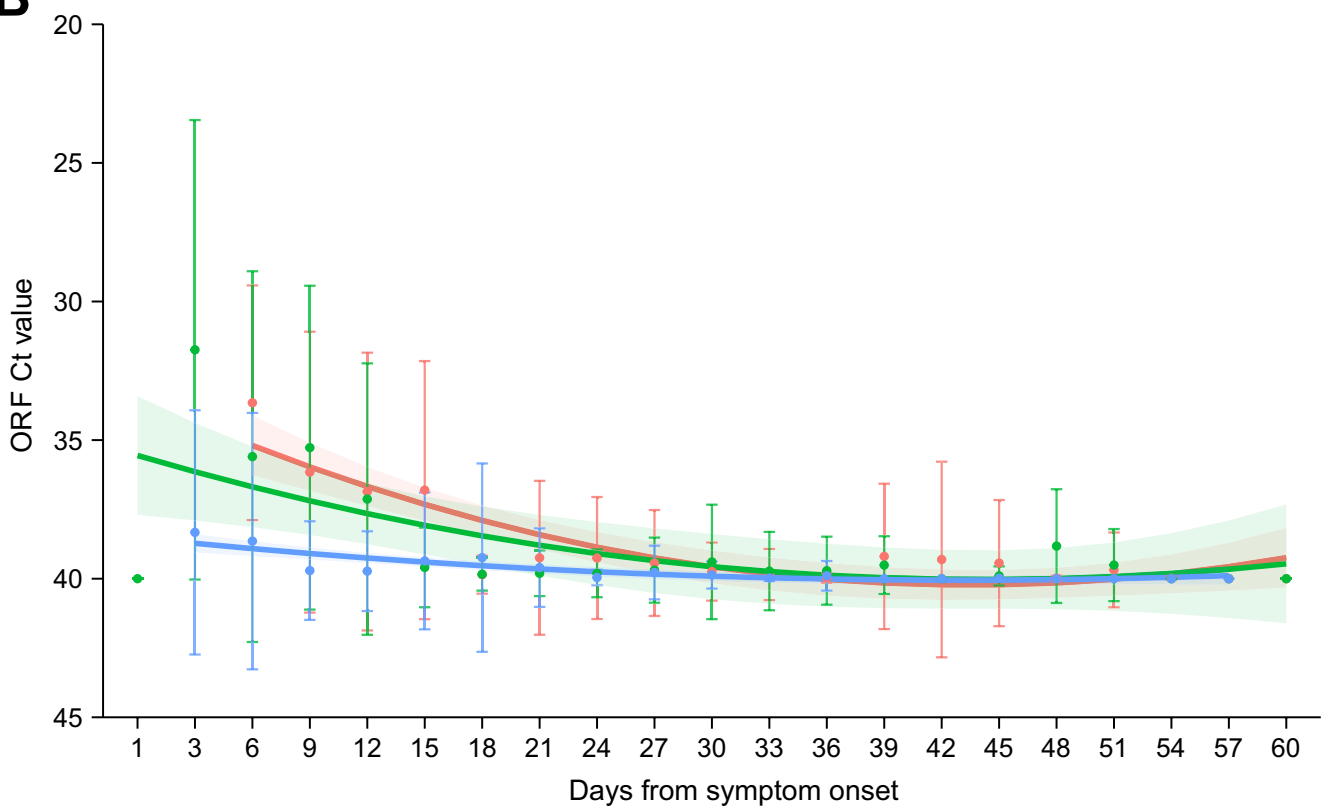

Fig. 3 Dynamic profile on viral loads detected by $\mathrm{N}$ gene (A) and ORF gene (B) among COVID-19 patients across the outbreak periods. Three periods (early, middle and late) were approximate equally classified based on the date of symptom onset of the included patients: 1st-24th January 2020 (red line, 229 patients), 25th-30th January 2020 (green line, 245 patients), and 31st January-5th March 2020 (blue line, 228 patients). Dots and error bars denote means and SDs, respectively

16]. Here based on a large sample size of symptomatic patients, we simulated a curve that was reflective of the dynamic profile of viral load, we can determine the viral RNA level that could be derived from a patient but only limited to patients with symptomatic infection, while not for those with asymptomatic infection.

The test based on two genes displayed different duration of SARS-CoV-2 RNA positive test, which was longer 
for $\mathrm{N}$ gene than ORF1ab gene, possibly indicating the higher sensitivity of assay for $\mathrm{N}$ gene than for the ORF1ab gene. Based on evaluation of either gene, duration of viral shedding appeared to be longer in patients of older age. This finding was similar to the previous studies of Zheng's study, in which viral load could persist for nearly 30 days in the patients of older than 60 years old [8]. A more prolonged shedding was also seen in female patients and those hospitalized with longer delay, as revealed by survival analysis and Kaplan-Meier curves, which is consistent with the findings from Zhou et al. [17] and Shu et al. [18]. Recent studies have shown that both age and sex had a considerable effect on the outcome of infections and have been associated with underlying differences in immune responses to infection. In the context of COVID-19, both age and sex disparity in disease severity had been displayed, potentially through different immunological mechanisms of disease progression between sex and ages. Takehiro Takahashi's study had provided robust evidence showing substantial differences in the baseline immune capabilities between male and female patients [19]. Among all the differences, female tend to have more Th2-driven immunity in response to pathogens than male [20]. Shearer et al. have proposed aging can lead to a Th1/Th2 imbalance that older individuals are more likely to have a Th2-type dominance [21]. Th1 (including IL-2 and IFN- $\gamma$ ) have been identified to participate in the virus clearance while Th2 cytokine IL-10 serves as a potent inhibitor of Th1 effectors cells [22]. In the premise of different Th1/Th2 induction, it's logical to determine that female and the older patients were more likely to have prolonged viral shedding.

On the other hand, although disease severity had been frequently related to viral loads, viral duration and viremia in previous studies [8,23, 24], we failed to determine significant difference in the timing of viral negativity between patients with different severity in the current study. For one reason, the potential correlation might have been compromised by the robust effect from age on the disease severity. This could also be explained by an insufficient data set, where many non-survivors tended to have few consecutive sampling points available, hindering a further assessment of prolonged viral shedding in related to severe disease. According to numerous studies that have addressed the correlation between viral shedding and COVID-19-associated symptoms, the mean period of SARS-CoV-2 viral shedding were slightly higher in patients with COVID-19-associated symptoms compare to asymptomatic patients $(25.0 \pm 7.8$ vs. $23.4 \pm 8.9, \mathrm{P}=0.051)$, however, the proportion of symptomatic patients with viral shedding $>24$ days were significantly higher than asymptomatic group [25]. Consistently, a study of 71 patients showed shorter duration of viral shedding in asymptomatic patients than symptomatic group [26]. Specific clinical symptoms, such as fever, have also been associated with longer periods of viral RNA shedding, with OR (95\%CI) of $5.200(1.190-22.726)$ in a study performed in China [27]. Here we failed to identify any specific symptoms that could be related to duration of viral shedding, which however, need to be replicated by further large scale analysis.

From the start of the disease onset, there was a difference in viral RNA level between patients who were sick earlier, and the difference was also decreasing with the time since onset of symptoms. Hypotheses to explain this decrease are numerous and one of them is that increasing immunity in the population could contribute to the lower viral loads by reaching a herd immunity threshold as the outbreak progressed. There are also other possibilities that as the outbreak progressed, the awareness of the disease could have increased among the population, with more mild patients seeking medical care at late epidemic, whereas early in the outbreak more severe cases with expected higher viral shedding were tested. This bias although might have been adjusted by multivariate analysis, was ineradicable. Another finding is the correlation between the low COVID-19-specific IgM antibodies and the high initial viral loads observed from the infected patients, indicating the inefficiency of the patients in producing humoral immunity against the virus.

Our study has several limitations. First, the high median $\mathrm{Ct}$ value tested at symptom onset when the viral loads was supposed to be very high might be related to detection instruments, assays or operators. Second, no test was performed for asymptomatic cases, thus whether the results will remain same with reference to the asymptomatic group cannot be addressed at this moment. In addition, some of the predesigned sampling was missing, which might cause bias in estimating the viral shedding due to the inequivalent sampling and reduced sample size. Especially for the non-survivors, only sparse points of sampling were performed for tests due to the emergency situation, thus the data of non-survivors is insufficient to be applied in the detailed analysis on the viral kinetics or related factors. Third, although predominant part of the patients received antiviral therapy during their hospitalization, detailed information on the therapy dosage or duration were not collected, therefore how the antiviral treatments can affect the viral replication cannot be evaluated in the current study.

In conclusion, we displayed the temporal viral shedding along the hospitalization duration. The temporal course of viral loads that was simulated by viral dynamics trajectory based on $\mathrm{N}$ gene and ORF gene allowed for a prediction of the SARS-CoV-2 virus at different clinical 
stages. These findings could serve as better guidance for the duration of infection prevention measures.

\section{Supplementary Information}

The online version contains supplementary material available at https://doi. org/10.1186/s12879-021-07002-w.

Additional file 1: Table 1. Demographics and clinical characteristics of COVID-19 patients between SVS and LVS groups. Table 2. The association between delayed time to SARS-COV-2 RNA negativity and symptoms on admission for COVID-19 patients. Table 3. Outbreak kinetics of SARS$\mathrm{CoV}-2$ viral loads level over three outbreak stages expressed as $\mathrm{N}$ and ORF Ct value for COVID-19 patients. Figure 1. IgM and IgG antibody titers compared between patients with high vs. low viral loads based on $\mathrm{N}$ gene ( $A$ and $C$ ) and ORF gene (B and D).

\section{Acknowledgements}

We pay enormous tribute to all medical staff and health practitioners who have contributed to fight against the disease of COVID-19.

\section{Authors' contributions}

Conception and design: WL, QBL. Collection and assembly of data: HL, HLZ, QW, QMW. Analysis and interpretation of the data: WL, QBL, JZ. Drafting of the article:WL, QBL, JZ. Statistical expertise: QBL. Critical revision of the article for important intellectual content: WL, QBL, LQF. All authors read and approved the final manuscript.

\section{Funding}

This study was supported by the National Natural Science Foundation of China (81825019) and Capital's Funds for Health Improvement and Research (2021-1 G-4271). The funding agencies had no role in study design, data collection and analysis, decision to publish, or preparation of the manuscript.

\section{Availability of data and materials}

After publication, the data and materials used in the study will be made available to others upon a proper request from the corresponding author Wei Liu at Iwbime@163.com or liuwei@bmi.ac.cn.

\section{Declarations}

\section{Ethical approval and consent to participate}

The study was conducted in accordance with guidelines and it is approved by the Ethics Committees from Tongji hospital (TJ-IRB20200102) and Tianyou hospital (202002). The Research Ethics Committees waived the requirement of informed consent before the study started because of the urgent need to collect epidemiological and clinical data. All the data were analyzed anonymously.

\section{Consent for publication}

Not applicable.

\section{Competing interests}

The authors declare that they have no competing interests.

\section{Author details}

${ }^{1}$ Tianyou Hospital, Wuhan University of Science and Technology, Wuhan, Hubei, People's Republic of China. ${ }^{2}$ State Key Laboratory of Pathogen and Biosecurity, Beijing Institute of Microbiology and Epidemiology, Beijing, People's Republic of China. ${ }^{3}$ Department of Laboratory Medicine, Tongji Hospital, Tongji Medical College, Huazhong University of Science and Technology, Wuhan, People's Republic of China. ${ }^{4}$ Department of Laboratorial Science and Technology, School of Public Health, Peking University, Beijing, People's Republic of China. Institute of Infection, Immunology and Tumor Microenvironment, Hubei Province Key Laboratory of Occupational Hazard Identification and Control, Medical College, Wuhan University of Science and Technology, Wuhan, People's Republic of China.
Received: 25 May 2021 Accepted: 21 December 2021

Published online: 27 December 2021

\section{References}

1. World Health Organization. Coronavirus disease (COVID-19) technical guidance: laboratory testing for 2019-nCoV in humans. Available from: https://www.who.int/emergencies/diseases/novel-coronavirus-2019.

2. Zou L, Ruan F, Huang M, Liang L, Huang H, Hong Z, et al. SARS-CoV-2 viral load in upper respiratory specimens of infected patients. N Engl J Med. 2020;382:1177-9.

3. Holshue ML, DeBolt C, Lindquist S, Lofy KH, Wiesman J, Bruce H, et al. First case of 2019 novel coronavirus in the United States. N Engl J Med. 2020;382:929-36.

4. Wu Y, Guo C, Tang L, Hong Z, Zhou J, Dong X, et al. Prolonged presence of SARS-CoV-2 viral RNA in faecal samples. Lancet Gastroenterol Hepatol. 2020;5:434-5.

5. Lan L, Xu D, Ye G, Xia C, Wang S, Li Y, et al. Positive RT-PCR test results in patients recovered from COVID-19. JAMA. 2020;323:502-1503.

6. Wu Z, McGoogan JM. Characteristics of and important lessons from the coronavirus disease 2019 (COVID-19) outbreak in China. JAMA. 2020;323:1239-42.

7. Liang WH, Guan WJ, Li CC, Li YM, Liang HR, Zhao Y, et al. Clinical characteristics and outcomes of hospitalised patients with COVID-19 treated in Hubei (epicentre) and outside Hubei (non-epicentre): a nationwide analysis of China. Eur Respir J. 2020;55:2000562.

8. Zheng S, Fan J, Yu F, Feng B, Lou B, Zou Q, et al. Viral load dynamics and disease severity in patients infected with SARS-CoV-2 in Zhejiang province, China, January-March 2020: retrospective cohort study. BMJ. 2020;369:m1443.

9. Yu X, Sun S, Shi Y, Wang H, Zhao R, Sheng J. SARS-CoV-2 viral load in sputum correlates with risk of COVID-19 progression. Crit Care. 2020;24:1-4.

10. Centers for Disease Control and Prevention. Coronavirus Disease 2019. Laboratories. Available from: https://www.cdc.gov/coronavirus/2019nCoV/lab/index.html.

11. World Health Organization. Coronavirus disease (COVID-19) outbreak situation. Available from: https://www.who.int/emergencies/diseases/ novel-coronavirus-2019.

12. China National Health Commission. Chinese clinical guidance for COVID19 pneumonia diagnosis and treatment (7 edition). Available from: http:// kjfy.meeting.so/msite/news/show/cn/3337.html.

13. He X, Lau EHY, Wu P, Deng X, Wang J, Hao X, et al. Temporal dynamics in viral shedding and transmissibility of COVID-19. Nat Med. 2020;26:672-5.

14. To KKW, Tsang OTY, Leung WS, Tam AR, Wu TC, Lung DC, et al. Temporal profiles of viral load in posterior oropharyngeal saliva samples and serum antibody responses during infection by SARS-CoV-2: an observational cohort study. Lancet Infect Dis. 2020;20:565-74.

15. Zhou F, Yu T, Du R, Fan G, Liu Y, Liu Z, et al. Clinical course and risk factors for mortality of adult inpatients with COVID-19 in Wuhan, China: a retrospective cohort study. Lancet. 2020;395:1054-62.

16. Lescure FX, Bouadma L, Nguyen D, Parisey M, Wicky PH, Behillil S, et al. Clinical and virological data of the first cases of COVID-19 in Europe: a case series. Lancet Infect Dis. 2020;20:697-706.

17. Zhou M, Yu FF, Tan L, Zhu YD, Ma N, Song LJ, et al. Clinical characteristics associated with long-term viral shedding in patients with coronavirus disease 2019. Am J Transl Res. 2020;12:6954-64.

18. Shu HM, He S, Sun Y, Lin CQ, Lu YF, Liu J, et al. Factors influencing viral clearance in mild COVID-19 and clinical characteristics of asymptomatic patients. Biomed Res Int. 2021;2021:5909612.

19. Takahashi T, Ellingson MK, Wong P, Israelow B, Lucas C, Klein J, et al. Sex differences in immune responses that underlie COVID-19 disease outcomes. Nature. 2020;588:315-20.

20. Klein SL, Flanagan KL. Sex differences in immune responses. Nat Rev Immunol. 2016;16:626-38.

21. Shearer GM. Th1/Th2 changes in aging. Mech Ageing Dev. 1997;94:1-5.

22. Wang JY, Liu P. Abnormal immunity and gene mutation in patients with severe hepatitis-B. World J Gastroenterol. 2003;9:2009-11.

23. Li H, Gu X, Li H, Gong F, Xu J, Wang Y, et al. Risk factors of viral RNAaemia and its association with clinical prognosis among patients with severe COVID-19. Chest. 2021;159:1382-6. 
24. Veyer D, Kernéis S, Poulet G, Wack M, Robillard N, Taly V, et al. Highly sensitive quantification of plasma SARS-CoV-2 RNA sheds light on its potential clinical value. Clin Infect Dis. 2020. https://doi.org/10.1093/cid/ciaa1196.

25. Kim B, Sohn JW, Nam S, Sohn JW, Choi WS, Kim HS. Factors associated with the delayed termination of viral shedding in COVID-19 patients with mild severity in South Korea. Medicina (Kaunas). 2020;56:659.

26. Kim SE, Jeong HS, Yu Y, Shin SU, Kim S, Oh TH, et al. Viral kinetics of SARSCoV-2 in asymptomatic carriers and presymptomatic patients. Int J Infect Dis. 2020;95:441-3.

27. Qi L, Yang Y, Jiang D, Tu C, Wan L, Chen X, et al. Factors associated with the duration of viral shedding in adults with COVID-19 outside of Wuhan, China: a retrospective cohort study. Int J Infect Dis. 2020;96:531-7.

\section{Publisher's Note}

Springer Nature remains neutral with regard to jurisdictional claims in published maps and institutional affiliations.

- fast, convenient online submission

- thorough peer review by experienced researchers in your field

- rapid publication on acceptance

- support for research data, including large and complex data types

- gold Open Access which fosters wider collaboration and increased citations

- maximum visibility for your research: over $100 \mathrm{M}$ website views per year

At BMC, research is always in progress.

Learn more biomedcentral.com/submissions 